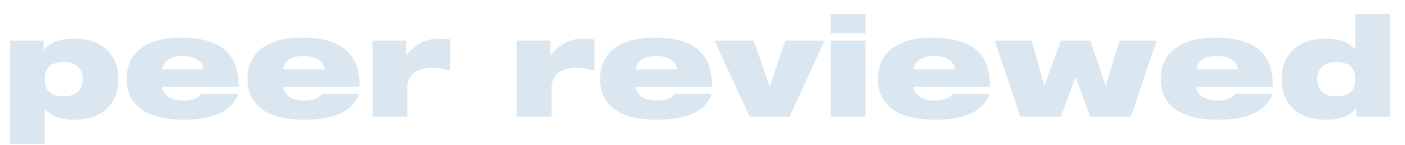

\title{
Risk management of paratuberculosis in dairy herds
}

\author{
Maarten F. Weber
}

Risk management of paratuberculosis (Johne's disease) in a dairy herd requires an assessment of the likelihood of paratuberculosis occurring in the herd, the economic impact of paratuberculosis on the herd and an evaluation of measures that can be taken to reduce this likelihood and impact.

The likelihood of paratuberculosis occurring in the herd is related to the regional herd-level prevalence of paratuberculosis and the herd management (e.g., introducing animals from other herds). The economic impact of paratuberculosis includes production losses due to subclinical and clinical cases, losses due to increased replacement of animals and costs of control measures. Furthermore, a reduction of the price of milk from infected herds might result from consumer concerns about the zoonotic potential of paratuberculosis.

Measures that reduce the likelihood of paratuberculosis occurring in a herd and its impact include preventive management measures (e.g., closed herd management and an effective separation of susceptible young stock from adult cattle), test-and-cull schemes for known infected herds and quality assurance schemes for test-negative herds. Quality assurance schemes for test-negative herds, such as schemes for 'low-Map bulk milk' and 'Map-free' herds, aim at safeguarding or increasing the profitability of these herds.

Keys to success of risk management of paratuberculosis include realistic expectations of the results of paratuberculosis control, quality assurance and control programmes that are appreciated by farmers and incentives for farmers to participate in such programmes.

Irish Veterinary Journal

Volume 59 (I0) 555-56I, 2006

Keywords: Dairy cattle, Johne's disease, Paratuberculosis, Risk management.

\section{Introduction}

Paratuberculosis (Johne's disease) is a chronic inflammatory bowel disease, primarily affecting ruminants. The aetiologic agent is Mycobacterium avium subsp. paratuberculosis (Map). Losses associated with paratuberculosis include failure to thrive, reduced milk production, reduced reproductive performance, reduced culling value and increased replacement rate (Whitlock and Buergelt, 1996; Hutchinson, 1996). Moreover, there are potential concerns about the safety of dairy products (Stabel, 2000).

Risk management of paratuberculosis is the process of identifying measures or actions that reduce the risk of exposure of a herd to Map to an acceptable level. This risk is a function of the probability of an adverse effect and the severity of that effect, consequential to exposure to Map. Therefore, risk management of paratuberculosis in a dairy herd requires an assessment of the likelihood of paratuberculosis occurring in the herd and the economic impact of paratuberculosis on the herd. Also, an assessment of measures that can be taken to reduce this likelihood and impact are required. These assessments should be made in view of goals of the farmer, such as

\section{Author for correspondence:}

Maarten F. Weber

Animal Health Service

P.O. Box 9

7400 AA Deventer, the Netherlands

Telephone:003I 570660379

Email:m.weber@gdvdieren.nl herd size, milk production, product quality and the time span the farmer aims to remain in the farming industry and of constraints such as resources for paratuberculosis control. Finally, risk management of paratuberculosis requires definition of an acceptable level of the risk of losses due to paratuberculosis. Depending on this acceptable level, paratuberculosis control can aim at suppression (control) of the infection or even eradication of Map.

\section{Likelihood of paratuberculosis occurring in a herd}

The likelihood of paratuberculosis occurring in a herd is related to the history of the herd, the (regional) herd-level prevalence and the herd management.

Not surprisingly, cows in herds with a history of clinical signs of paratuberculosis are more likely to be test-positive than cows in a herd without such history (Obasanjo et al., 1997; Hirst et al., 2004).

Prevalence studies have been performed in several countries. Thirty per cent of 143 herds in three Irish counties had one or more seropositive cattle (Barrett, personal communication). This compares with $55 \%$ of herds with seropositive cattle in the Netherlands (Muskens et al., 2000). However, in the latter study, there were significant regional differences. Furthermore, given the proportion of test-positive herds, the estimated proportion of truly infected herds is largely dependent on the specificity of the test being used (Muskens et al., 2000).

Cattle in large herds, and in herds in which animals were bought in from other herds, are more likely to be test-positive (Wells and 
Wagner, 2000; Hirst et al., 2004; Weering et al., 2005). Furthermore, factors that increase exposure of susceptible calves to Map such as exposure of calves to faeces of adult cows, group housing for periparturient cows and group housing for pre-weaned calves increased the risk of cattle or herds to be test positive (Obasanjo et al., 1997; Johnson-Ifearulundu and Kaneene, 1999; Wells and Wagner, 2000). Also, cleaning maternity pens after each use was associated with a reduced risk of a herd being test-positive (Johnson-Ifearulundu and Kaneene, 1998).

If information on the infection status of a herd is not available, culture of Map in environmental samples can indicate whether or not Map is present in the herd. In a recent study, more than $75 \%$ of herds with faecal culture positive cattle were detected by culturing four or five samples from the cows' environment such as the milk parlour exit, the floor of the holding pen, a common alleyway, or the manure pit (Lombard et al., 2005).

\section{Economic impact of paratuberculosis}

The economic impact of paratuberculosis includes production losses due to sub-clinical and clinical cases, losses due to increased replacement of animals and costs of control measures. Because most cases of paratuberculosis are subclinical, and precise prevalence data are often lacking, it is difficult to assess the economic consequences of paratuberculosis (National Research Council, 2003). For instance, estimates of milk production losses are inconsistent. Some studies found equivalent or even higher milk productions in test-positive animals (McNab et al., 199I; Johnson et al., 200I). Other studies showed losses in test-positive animals of up to $19.5 \%$ of the 0 to 305 days-in-milk production, depending on parity (Benedictus et al., 1987; Wilson et al., 1993; Sweeney et al., 1994; Kudahl et al., 2004). However, using simulation modelling, an overall mean annual loss of $\$ 35$ per cow, increasing to $\$ 72$ per cow per year after 20 years was estimated for a typical 100-head US dairy herd (Groenendaal and Galligan, 2003). Similarly, in a recent Scottish study, annual losses were estimated at $£ 27$ per cow (Stott et al., 2005).

More importantly than direct losses, a milk price reduction for infected herds can result from consumer concerns about the zoonotic potential of paratuberculosis. The issue of a potential role of Map in the pathogenesis of Crohn's disease in humans has not yet been resolved (European Commission, 2000; Food Safety Authority of Ireland, 2000; Chacon et al., 2004; Herrewegh et al., 2004). If Map is implicated, then milk is a possible vehicle of transmission of the organism to humans, because Map has been detected in raw milk and might not be effectively inactivated by pasteurisation (Sweeney et al., 1992; Streeter et al., 1995; Grant et al., 1996; Millar, 1996; Sung and Collins, 1998; Grant et al., 1999; Giese and Ahrens, 2000; Corti and Stephan, 2002; Gao et al., 2002; Grant et al., 2002a, b; MacDonald et al., 2002; Pillai and Jayaro, 2002; Sevilla et al., 2002).

\section{Control of paratuberculosis and its impact}

The key element in prevention of introduction of Map into a dairy herd is a closed herd management i.e., no introduction of cattle from other herds. Trade of cattle is the main route of between-herd transmission of Map (Sweeney, 1996). A closed herd management is feasible if young stock are raised in the herd: a one-year study (Sept 200I - Aug 2002; Velthuis, 2004) found that, amongst Dutch dairy herds in which young stock were raised, $55 \%$ of herds were closed. However, when introduction of cattle into dairy herds is necessary to achieve goals of farmers (such as optimising production), purchasing cattle from certified Map-free cattle herds only is highly recommended. Tests for paratuberculosis are too insensitive to avoid introduction of Map if only the introduced cattle are tested.Therefore, certified Map-free herds are important in a control programme for paratuberculosis as a source of non-infected cattle. Certification programmes to identify Map-free herds have been developed in several countries (Kennedy et al., 200I). In the Netherlands, a certification-and-surveillance programme has been developed in which herds can obtain 'Map-free' status following five negative annual herd examinations (the first herd examination by ELISA and faecal culture of ELISA-positive animals, the second to fifth examinations by pooled faecal culture: Benedictus et al., 1999; Weber et al. 2004).

In infected herds, reducing the infection pressure on susceptible animals is paramount. It is generally assumed that the majority of infected cattle have been infected during the first six to 12 months of life. Several options to reduce the infection pressure on susceptible calves are available. Firstly, preventive management measures that reduce contact between the susceptible calves and infectious adult cattle are generally advised. Map is shed in faeces, colostrum and milk of infectious cattle. A checklist including preventive measures can be used in advising farmers (Tables I to 3). Secondly, vaccination has been advocated. However, although vaccination does reduce clinical disease and economic losses of paratuberculosis, it does not reduce transmission of Map (van Schaik et al., 1996; Kalis et al., 200I). Thirdly, the infection pressure can be reduced by a test-and-cull scheme. Tests frequently used in control programmes for known infected herds are individual faecal culture, pooled faecal culture and serum-ELISA. The diagnostic characteristics of these tests very much depend on the stage of the infection-and-disease process: animals at a progressed stage are more likely to be detected. Because at any point in time only a small proportion of infected animals is at such a progressed stage of infection, the overall sensitivity (i.e., detection rate of infected animals) is low. Estimates of the overall sensitivity of individual faecal culture range from $20 \%$ to $55 \%$ (Sockett et al., 1992; Whitlock et al., 2000; Nielsen et al., 2002). Strategically pooled faecal culture, in which faecal samples of five animals stratified by age are pooled, was found to have a relative sensitivity of $86 \%$ compared to individual faecal culture (Kalis et al. 2000). The serum-ELISA currently used at our laboratory (ELISA Bovine Paratuberculosis Serum Verification, Pourquier Institute, France) was found to have a relative sensitivity of $41 \%$ compared to individual faecal culture (van Maanen, 2002). However, the test characteristics need to be balanced against the costs of the various tests. For example, at our laboratory, costs (2006) of individual faecal culture are $€ 30.26$ per sample, costs of pooled faecal culture are $€ 43.34$ per pool of five samples and costs of ELISA are €7.II per sample (excluding VAT). However, because of the low sensitivity of tests, testing in a control programme needs to be repeated at regular intervals (for instance, once per year) to reduce the infection pressure on susceptible animals. 
Table I: Preventive management measures around birth of calves that are to be retained in the herd

- A functioning separated calving area is available

- The calving area cannot be contaminated by faeces from cattle outside the calving area

- Calving cattle are always housed individually in the calving area, with a wall between them that prevents cross-contamination by faeces

- The calving area is thoroughly cleaned and free of faeces prior to each calving

- Calves are born in a thick layer of clean straw or on a clean sheet

- The calving area is used for calving only

- At least $90 \%$ of cattle calve in the calving area or in a 'clean' field (on which slurry has not been spread and cattle have not grazed recently)

- Calves are separated from their dams immediately after birth

- Each calf born unhygienic (i.e., not in the calving area or in a 'clean' field), is moved off the farm before one month of age

\section{Table 2: Preventive management measures between birth and weaning of calves that are to be retained in the herd}

- Calves are fed colostrum from their own dam only

- Calves are fed artificial milk replacer instead of cow's milk (except colostrum)

- After each feeding, milk buckets are thoroughly cleaned with hot water $\left(>40^{\circ} \mathrm{C}\right)$, or each calf has its own bucket

- The water supply of calves is not connected to the water supply of adult cattle, such that cross contamination can occur, and calves are not supplied with surface water

- Calves are never grazed on fields or fed grass or grass silage harvested from fields on which, earlier that year, adult cattle have grazed or slurry from adult cattle has been applied

- Calves are fed roughage in a trough that has been positioned in a way that prevents contamination of roughage with faeces of adult cattle

- Calves are housed in a separate barn or separate compartment of a barn and pastured separately, without any contact with (faeces of) adult cattle

- In the barn or compartment in which calves are housed, separate clothing and boots are used (to prevent contamination with faeces of adult cattle), or calves are taken care of by a different stockman than the adult herd

- Calves are never in contact with (faeces of) sheep or goats, and never grazed on fields in which sheep or goats have been grazed or to which sheep or goat manure has been applied in the same year

\section{Table 3: Preventive management measures between weaning and one year of age of calves that are to be retained in the herd}

- Calves are housed in a separate barn or separate compartment of a barn, without any contact with (faeces of) adult cattle

- In the barn or compartment in which calves are housed, separate clothing and boots are used (to prevent contamination with faeces of adult cattle), or calves are taken care of by a different stockman than the adult herd

- The water supply of calves is not connected to the water supply of adult cattle, such that cross contamination can occur, and calves are not supplied with surface water

- Calves are never grazed on fields simultaneously with adult cattle, and never grazed in fields or fed grass or grass silage harvested from fields on which, earlier that year, adult cattle have grazed or slurry from adult cattle has been applied

- Calves are fed roughage in a way that prevents contamination of roughage with faeces of adult cattle

- Calves are never in contact with (faeces of) sheep or goats, and never grazed on fields in which sheep or goats have been grazed or to which sheep or goat manure has been applied in the same year 


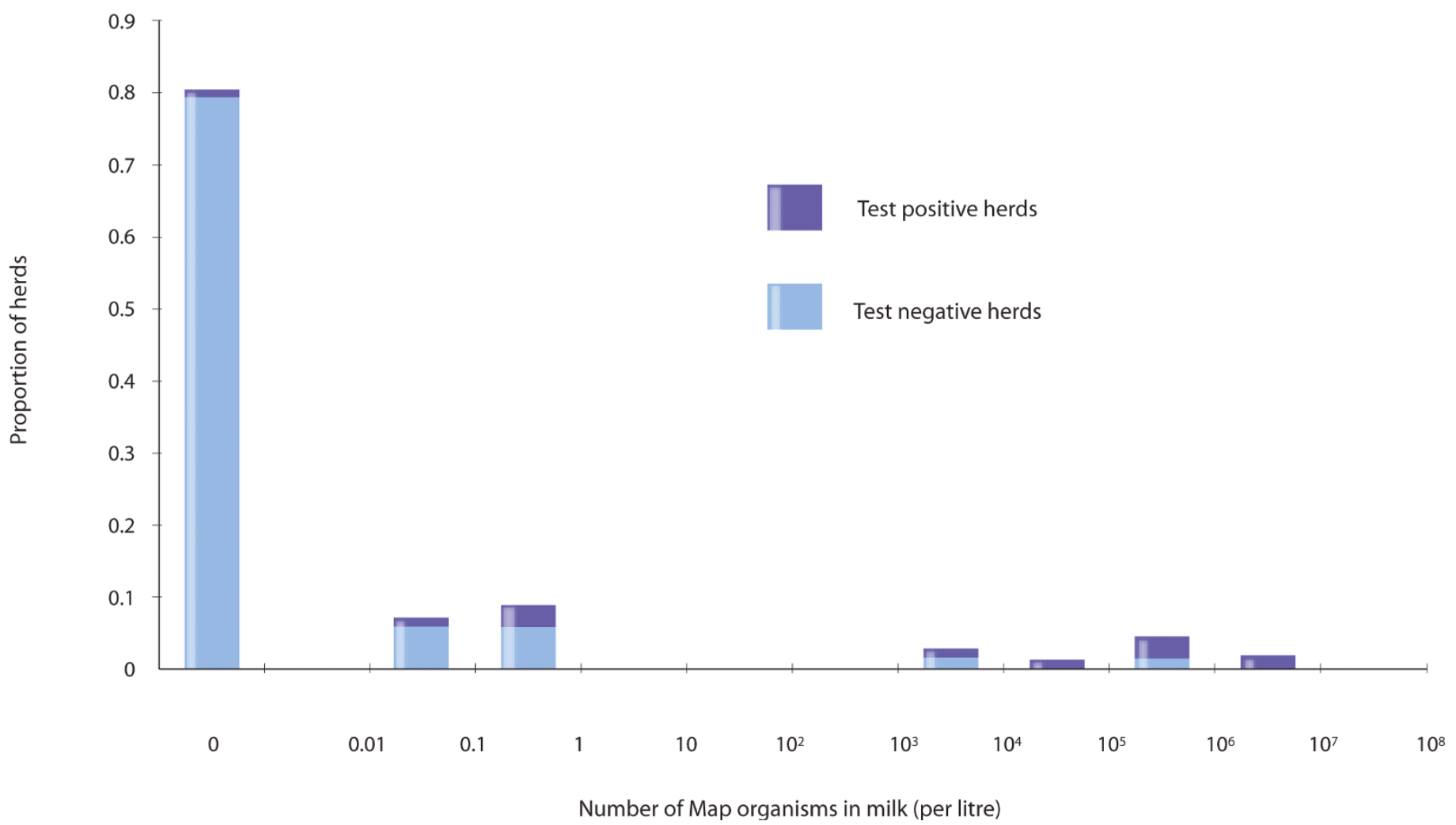

Figure I. Estimated number of Map organisms per litre of bulk milk immediately after an initial assessment in simulated herds that were test-negative (and therefore certified as 'low-Map bulk milk') and test-positive at that assessment, in a simulation of a bulk milk quality assurance programme in closed Dutch dairy herds (Weber et al., 2005).

So far, neither preventive management measures alone, nor a testand-cull scheme alone have been shown to give reliable results in a majority of Map-infected herds. Therefore, in known infected herds, it is strongly advisable to combine vigorous execution of preventive management measures together with a test-and-cull scheme. With respect to test-and-cull, farmers aiming at elimination of Map are advised to annually test all cattle of two years of age and older by faecal culture. Farmers aiming at suppression rather than elimination of Map, can consider using an ELISA instead. However, culling based on faecal culture is more effective (Weber et al., 2005), because of the higher sensitivity of faecal culture. Positive ELISA results can be confirmed by faecal culture; however, in infected herds this is needless if an ELISA with a high specificity is used (more than 99\%). In these herds, it is advisable to cull all test-positive cattle and their lastborn calves. Furthermore, veterinary practitioners are advised to regularly do a 'reality check', to monitor the implementation of the control programme that was intended by the farmer.

It is widely recognised that the most effective way to reduce any potential human health risk of exposure to Map through consumption of dairy products is to control and prevent paratuberculosis in the national dairy herd (O'Reilly et al., 2004). Therefore, the potential losses to the dairy industry due to consumer concerns about milk safety might be reduced by implementation of a milk quality assurance programme for paratuberculosis in dairy herds. Such a quality assurance programme has recently been developed for Dutch dairy herds (van Roermund et al., 2005; Weber et al., 2005). In the programme, herds are certified as 'low-Map bulk milk' if, with a certain probability, the concentration of Map in bulk milk does not exceed a maximum acceptable concentration (MAC). The MAC was set at $10^{3}$ Map organisms per litre of bulk milk, based on pasteurisation studies (Weber et al., 2005). This does not necessarily mean that a 'low-Map bulk milk' herd is free of Map. Therefore, such a milk quality assurance programme can be run at considerable lower costs than a certification-and-surveillance programme for 'Map-free' herds. The milk quality assurance programme starts with an initial assessment; test-negative herds enter a surveillance procedure and test-positive herds enter a control procedure. Although quantification of Map in bulk milk might seem the preferred method to distinguish between 'low-Map bulk milk' herds and other herds, methods to routinely quantify Map in large numbers of bulk milk samples are not yet available. Therefore, test schemes rely on serology and faecal culture. The initial assessment is done by a single serological herd examination. Surveillance is done by biennial serological herd examinations. The control procedure in test-positive herds is done by annual serological herd examinations or by biennial herd examinations by faecal culture. Herd examinations by serology and by faecal culture include all cattle of three years of age and older, and two years of age and older, respectively. Using a stochastic simulation model of paratuberculosis transmission in dairy herds (JohneSSim; Groenendaal et al., 2002), it was shown that such a programme effectively ensures the quality of 'low-Map bulk milk': more than $96 \%$ of certified herds were below the MAC of $10^{3}$ Map organisms per litre of bulk milk (Figure I; Weber et al., 2005). It should be realised that animals in an advanced stage of infection (high shedders) contribute most to the contamination of bulk milk. Serology and faecal culture have a relative high sensitivity in 
these animals. Therefore, these animals are relatively easily detected when tested repeatedly. However, a closed herd management and vigorous execution of preventive management measures were found essential to increase the probability of obtaining and keeping a 'lowMap bulk milk' status (van Roermund et al., 2005; Weber et al., 2005).

\section{Discussion}

Several keys to success of risk management of paratuberculosis can be identified on the herd level, on the veterinary practice level as well as on the national level. One of the keys to success on each of these levels is to have realistic expectations of the results of paratuberculosis control. Worldwide, the aim of control programmes nowadays shifts from eradication of Map to (only) suppression of the infection.

Keys to success for individual farmers include a closed herd management and a vigorous execution of preventive management measures. Farmers need to realise that many herds are infected at a low prevalence without the farmer noticing, and that in these cases the infection can spread rather quickly. Therefore, preventive management measures are also advised if clinical signs of paratuberculosis are absent. In known infected herds, or herds in which test results indicate an infection, combining preventive management measures with culling of animals that are (going to be) infectious is expected to be the key to success. As mentioned before, culling based on faecal culture is far more effective than culling based on ELISA (Weber et al., 2005). A prerequisite to success in known infected herds is to accept all positive test results as such. In known infected herds, positive ELISA results have a high predictive value, especially if an ELISA is used with a high specificity (more than 99\%). In that situation, more harm is done by not culling test-positive animals in which a conformation test is (false) negative, than by culling a false-positive animal.

A key to success for veterinary practitioners is a sound understanding of the epidemiology and control of paratuberculosis. Therefore, veterinary practitioners are encouraged to visit websites such as www.paratuberculosis.org and www.vetmedce.org to regularly update their understanding of the risk management of paratuberculosis.

A key to success of risk management of paratuberculosis on a national level is to develop a paratuberculosis programme in which a high proportion of herds participate. Even an excellent programme is useless if not appreciated by farmers or if incentives to participate are lacking. Therefore, involvement of the dairy processing industry in a paratuberculosis milk quality assurance programme is required. Milk price differentiation is supposed to be a powerful incentive to stimulate participation in a programme. However, the incentive should be directed towards achieving targets of the programme (such as a 'low-Map bulk milk' status) rather than towards participation in the programme as such. To reduce the economic effects on the dairy industry of potential consumer concerns about the safety of dairy products, a milk quality assurance programme can be an asset. Such a programme can be run at relatively low costs for the majority of participating herds, because 'low-Map bulk milk' herds do not necessarily need to be Map-free. Median total discounted costs for 20-year participation by a typical Dutch dairy herd (initial herd size of 65 adult cattle, with an annual increment of $5 \%$ ) in a programme consisting of an initial assessment by ELISA, surveillance by biennial ELISA and control by biennial faecal culture have been estimated at $€ 6,000$ per herd (Weber et al., 2005). Again, stimulating a closed herd management of participating herds is an essential key to increase the proportion of 'low-Map bulk milk' herds in the long term (van Roermund et al., 2005). However, because a closed herd management may not always be feasible, establishment of a nucleus of certified 'Map-free' herds, to enable low-risk trade of cattle, is another key to success on the national level. The paratuberculosis status of these 'nucleus' herds can be more intensively monitored.

It is concluded that the likelihood of paratuberculosis occurring in a herd and its economic impact are important issues in risk management of paratuberculosis in dairy herds. Measures that can be taken to reduce this likelihood and impact include closed herd management, preventive management measures, test-and-cull of infected animals and participation in quality assurance programmes, such as a programme for 'low-Map bulk milk'. Keys to success include realistic expectations of the results of paratuberculosis control, development of a quality assurance programme that is appreciated by farmers and incentives for farmers to participate in such a programme.

\section{Acknowledgements}

Comments of P. Hartigan, J. Verhoeff, G. van Schaik, P. Franken and A. Kummeling on the manuscript are gratefully acknowledged.

\section{References}

Benedictus, G., Dijkhuizen, A.A. and Stelwagen, J. (I 987) Economic losses due to paratuberculosis in dairy cattle. Veterinary Record I2I: |42-I46.

Benedictus, G., Verhoeff, J., Schukken, Y.H. and Hesselink, J.W. (1999) Dutch paratuberculosis programme: history, principles and development. Proceedings of the Sixth International Colloquium on Paratuberculosis, Melbourne, February 14 - 18, 1999, pp 9 - 21 .

Chacon, O., Bermudeze, L.E. and Barletta, R.G. (2004) Johne's disease, inflammatory bowel disease and Mycobacterium paratuberculosis. Annual Reviews of Microbiology 58: 329-363.

Corti, S. and Stephan, R. (2002) Detection of Mycobacterium avium subspecies paratuberculosis specific IS900 insertion sequences in bulk-tank milk samples obtained from different regions throughout Switzerland. BMC Microbiology 2: I5.

European Commission (2000) Possible links between Crohn's disease and paratuberculosis. Report, Scientific Committee on Animal Health and Animal Welfare, European Commission, 76 pp. http:// europa.eu.int/comm/food/fs/sc/scah/out38_en.pdf (accessed 2 Ist December 2004).

Food Safety Authority of Ireland (2000) Mycobacterium paratuberculosis. Does is contribute to Crohn's disease? Report, 15 pp. www.fsai.ie (accessed 10 October, 2005).

Gao, A., Mutharia, L., Chen, S., Rahn, K. and Odumeru, J. (2002) Effect of pasteurization on survival of Mycobacterium paratuberculosis in milk. Journal of Dairy Science. 85: 31 98-3205.

Giese, S.B. and Ahrens, P. (2000) Detection of Mycobacterium avium subsp. paratuberculosis in milk from clinically affected cows by PCR and 
culture. Veterinary Microbiology 77: 291-297.

Grant, I.R., Ball, H.J., Neill, S.D. and Rowe, M.T. (I996) Inactivation of Mycobacterium paratuberculosis in cows' milk at pasteurization temperatures. Applied Environmental Microbiology 62: 63I-636.

Grant, I.R., Ball, H.J. and Rowe, M.T. (1999) Effect of higher pasteurization temperatures, and longer holding times at 72 degrees $\mathrm{C}$, on the inactivation of Mycobacterium paratuberculosis in milk. Letters in Applied Microbiology 28: 46I-465.

Grant, I.R., Hitchings, E.I., McCartney, A., Ferguson, F. and Rowe, M.T. (2002a) Effect of commercial-scale high-temperature, short-time pasteurization on the viability of Mycobacterium paratuberculosis in naturally infected cow's milk. Applied Environmental Microbiology 68: 602-607.

Grant, I.R., Ball, H.J. and Rowe, N.T. (2002b) Incidence of Mycobacterium paratuberculosis in bulk raw and commercially pasteurized cow's milk from approved dairy processing establishments in the United Kingdom. Applied Environmental Microbiology 68: 24282435.

Groenendaal, H., Nielen, M., Jalvingh, A.W., Horst, S.H., Galligan, D.T. and Hesselink, J.W. (2002) A simulation of Johne's disease control. Preventive Veterinary Medicine 54: 225-245.

Groenendaal, H. and Galligan, D.T. (2003) Economic consequences of control programs for paratuberculosis in midsize dairy farms in the United States. Journal of the American Veterinary Medical Association 223: 1757-1763.

Hirst, H.L., Garry, F.B., Morley, P.S., Salman, M.D., Dinsmore, R.P., Wagner, B.A., McSweeney, K.D. and Goodell, G.M. (2004) Seroprevalence of Mycobacterium avium subsp. paratuberculosis infection among dairy cows in Colorado and herd-level risk factors for seropositivity. Journal of the American Veterinary Medical Association 225: 97-101.

Hutchinson, L.J. (1996) Economic impact of paratuberculosis. The Veterinary Clinics of North America: Food Animal Practice I2: 373-38I.

Herrewegh, A.A.P.M., Roholl, P.J.M., Overduin, P., van der Giessen, J.W.B. and van Soolingen, D. (2004) Is there evidence for a link between Crohn's disease and exposure to Mycobacterium avium ssp. paratuberculosis? A review of current literature. RIVM report 23008600 I/2004, 74 pp. (Accessed II October 2005).

Johnson-Ifearulundu, Y.J. and Kaneene, J.B. (1998) Managementrelated risk factors for $M$. paratuberculosis infection in Michigan, USA, dairy herds. Preventive Veterinary Medicine 37: 4I-54.

Johnson-Ifearulundu, Y. and Kaneene, J.B. (1999) Distribution and environmental risk factors for paratuberculosis in dairy cattle herds in Michigan. American Journal of Veterinary Research 60: 589-596.

Johnson, Y.J., Kaneene, J.B., Gardiner, J.C., Lloyd, J.W., Sprecher, D.J. and Coe, P.H. (200I) The effect of subclinical Mycobacterium paratuberculosis infection on milk production in Michigan dairy cows. Journal of Dairy Science 84: 2188-2194.

Kalis, C.H.J., Hesselink, J.W., Barkema, H.W. and Collins, M.T. (2000) Culture of strategically pooled bovine faecal samples as a method to screen herds for paratuberculosis. Journal of Veterinary Diagnostic Investigation I2: 547-55 I.

Kalis, C.H.J., Hesselink, J.W., Barkema, H.W. and Collins, M.T. (200I) Use of long-term vaccination with a killed vaccine to prevent faecal shedding of Mycobacterium avium subsp. paratuberculosis in dairy herds. American Journal of Veterinary Research 62: 270-4.

Kennedy, D., Holmström, A., Plym Forshell, K., Vindel, E. and Suarez Fernandez, G. (200I) On farm management of paratuberculosis (Johne's disease) in dairy herds. International Dairy Federation Bulletin 362: 18 - 31 .

KudahI, A., Nielsen, S.S. and J.T. Sørensen, J.T. (2004) Relationship between antibodies against Mycobacterium avium subsp. paratuberculosis in milk and shape of lactation curves. Preventive Veterinary Medicine 62: I 19-134.

Lombard, J.E., Smith, R.L., Wagner, B.A. and McCluskey, B.J. (2005) Evaluation of environmental sampling to determine distribution and herd infection status for Mycobacterium avium subspecies paratuberculosis. Proceedings of the Eight International Colloquium on Paratuberculosis, Kopenhagen, Denmark, I4-18 August 2005, PP 507510.

Van Maanen, C., Koster, C., van Veen, B., Kalis, C.H.J., Collins, M.T. (2002) Validation of Mycobacterium avium subsp. paratuberculosis antibody detecting ELISA's. Proceedings of the Seventh International Colloquium on Paratuberculosis, Bilbao, June 2002, 182.

McDonald, W.L., O'Riley, K.J., Schroen, C.J. and Condron, R.J. (2002) Heat inactivation of Mycobacterium avium subsp. paratuberculosis. Proceedings of the Seventh International Colloquium on Paratuberculosis, Bilbao, II-14 June 2002 pp 312-316.

McNab,W.B., Meek, A.H., Martin, S.W. and Duncan, J.R. (|99|) Associations between dairy production indices and lipoarabinomannan enzyme-immunoassay results for paratuberculosis. Canadian Journal of Veterinary Research 55: 356-36I.

Millar, D., Ford, J., Sanderson, J., Withey, S., Tizard, M., Doran, T. and Hermon-Taylor, J. (1996) IS900 PCR to detect Mycobacterium paratuberculosis in retail supplies of whole pasteurized cows' milk in England and Wales. Applied Environmental Microbiology 62: 3446-3452.

Muskens, J., Barkema, H.W., Russchen, E., van Maanen, K., Schukken, Y.H. and Bakker, D. (2000) Prevalence and regional distribution of paratuberculosis in dairy herds in The Netherlands. Veterinary Microbiology 77: 253 - 26I.

National Research Council (2003) Economic implications of Johne's Disease. In: Diagnosis and Control of Johne's Disease National Research Council: pp 9-103.

Nielsen, S.S., Grønbæk, C., Agger, J.F. and Houe, H. (2002) Maximum-likelihood estimation of sensitivity and specificity of ELISA's and faecal culture for diagnosis of paratuberculosis. Preventive Veterinary Medicine 53: 191-204.

Obasanjo, I.O., Grohn, Y.T. and Mohammed, H.O. (1997) Farm factors associated with the presence of Mycobacterium paratuberculosis infection in dairy herds on the New York State Paratuberculosis Control Program. Preventive Veterinary Medicine 32: 243-25I.

O'Reilly C.E., O'Connor, L., Anderson, W., Harvey, P., Grant, I.R., Donghy, J., Rowe, M. and O'Mahony, P. (2004) Surveillance of bulk raw and commercially pasteurized cows' milk from approved Irish liquid-milk pasteurization plants to determine the incidence of Mycobacterium paratuberculosis. Applied Environmental Microbiology 70: 5|38-5|44.

Pillai, S.R. and Jayarao, B.M. (2002) Application of IS900 PCR for detection of Mycobacterium avium subsp. paratuberculosis directly from raw milk. Journal of Dairy Science 85: 1052- 1057.

van Roermund, H.J.W., Weber, M.F., de Koeijer, A.A., Velthuis, 
A.G.J. and de Jong, M.C.M. (2005) Development of a milk quality assurance program for paratuberculosis: from within and between herd dynamics to economic decision analysis. Proceedings of the Eight Internarional Colloquium on Paratuberculosis, Copenhagen, August 14-18, 2005, pp 5I-59.

von Schaik, G. van, Kalis, C.H.J., Benedictus G., Dijkhuizen, A.A. and Huirne R.B. (1996) Cost-benefit analysis of vaccination against paratuberculosis in dairy cattle. Veterinary Record I39: 624-627. Sevilla, I., Aduriz, G., Garrido, J.M., Geijo, M.V. and Juste, R.A. (2002) A preliminary survey on the prevalence of paratuberculosis in dairy cattle in Spain by bulk milk PCR. Proceedings of the Seventh International Colloquium on Paratuberculosis, Bilbao, II-I4 June 2002, PP 332-336.

Sockett, D.C., Carr, D.J. and Collins, M.T. (1992) Evaluation of conventional and radiometric fecal culture and a commercial DNA probe for diagnosis of Mycobacterium paratuberculosis infections in cattle. Canadian Journal of Veterinary Research 56: I 48-I 53.

Stabel, J.R. (2000) Johne's disease and milk: do consumers need to worry? Journal of Dairy Science 83: 1659-63.

Stott, A.W., Jones, G.M., Humphry, R.W. and Gunn, G.J. (2005) Financial incentive to control paratuberculosis (Johne's disease) on dairy farms in the United Kingdom. Veterinary Record 26: 825-3I.

Streeter, R.N., Hoffsis, G.F., Bech-Nielsen, S., Shulaw, W.P. and Rings, D.M. (1995) Isolation of Mycobacterium paratuberculosis from colostrum and milk of subclinically infected cows. American Journal of Veterinary Research 56: 1322-4.

Sung, N. and Collins, M.T. (1998) Thermal tolerance of Mycobacterium paratuberculosis. Applied Environmental Microbiology 64: 999- 1005

Sweeney, R.W. (1996) Transmission of paratuberculosis. The Veterinary Clinics of North America: Food Animal Practice I 2: 305-3 2.

Sweeney, R.W., Whitlock, R.H. and Rosenberger, A.E. (1992) Mycobacterium paratuberculosis cultured from milk and supramammary lymph nodes of infected asymptomatic cows. Journal of Clinical Microbiology 30: 166-171.

Sweeney, R.W., Hutchinson, L.J., Whitlock, R.H., Galligan, D.T. and Spencer, P.A. (1994) Effect of Mycobacterium paratuberculosis infection on milk production in dairy cattle. Proc. 4th Int Coll Paratuberculosis, Cambridge, U.K., I7-2I July 1994, pp I33-I36.

Velthuis, A.G.J. (2004) The effect of regulations on the contact structure of the Dutch cattle sector. Proceedings Society for Veterinary Epidemiology and Preventive Medicine, Martigny, Switzerland, 24th - 26th March 2004, pp 200-215.

Weber, M.F., Groenendaal, H., van Roermund, H.J.W., and Nielen, M. (2004) Simulation of alternatives for the Dutch Johne's disease certification-and-monitoring program. Preventive Veterinary Medicine 62: I-I7.

Weber, M.F., van Roermund, H.J.W., Velthuis,A.G.J., de Koeijer, A.A., de Jong, M.C.M. and Nielen, M. (2005) Development of a milk quality assurance programme for paratuberculosis: stochastic simulation of within-herd infection dynamics and economics. Proceedings of the Eight International Colloquium on Paratuberculosis, Kopenhagen, Denmark, I4-I8 August 2005, pp 60-73.

Weering, H.J. van, Mars, M.H., Muskens, J., Middelesch, H. and van Schaik G. (2005) The effect of biosecurity measures for paratuberculosis on the seroprevalence in Dutch dairy herds.
Proceedings of the Eight International Colloquium on Paratuberculosis, Kopenhagen, Denmark, I4-I8 August 2005, pp 246-253.

Wells, S.J. and Wagner, B.A. (2000) Herd-level risk factors for infection with Mycobacterium paratuberculosis in US dairies and association between familiarity of the herd manager with the disease or prior diagnosis of the disease in that herd and use of preventive measures. Journal of the American Veterinary Medical Association 216 : I450-I457.

Whitlock, R.H. and Buergelt, C. (1996) Preclinical and clinical manifestations of paratuberculosis (including pathology). The Veterinary Clinics of North America: Food Animal Practice I 2: 345-356.

Whitlock, R.H., Wells, S.J., Sweeney, R.W. and van Tiem, J. (2000) ELISA and fecal culture for paratuberculosis (Johne's disease): sensitivity and specificity of each method. Veterinary Microbiology 77 : 387-398.

Wilson, D.J., Rossiter, C., Han, H.R. and Sears, P.M. (1993) Association of Mycobacterium paratuberculosis infection with reduced mastitis, but with decreased milk production and increased cull rate in clinically normal dairy cows. American Journal of Veterinary Research 54: 1851-1857. 